\title{
Heat Flow in a Right Circular Cylinder With Arbitrary Temperature Boundary Conditions-Applications to the Determination of Thermal Conductivity
}

\author{
D. R. Flynn
}

(August 5, 1964)

\begin{abstract}
Expressions are developed which permit calculation of the temperature-dependent thermal conductivity of a cylindrical specimen from the experimentally determined temperature distributions on its surfaces and from the heat flow through a central circular area at one end of the cylinder. Numerical factors are tabulated which permit rapid hand computation of thermal conductivity values from experimental data for the case of axially symmetric parabolic boundary conditions on the flat surfaces and a linear longitudinal temperature distribution on the convex surface. Applications to several published methods of thermal conductivity determinations are shown and examples are given.
\end{abstract}

\section{Introduction}

In a recent paper by Glaser et al. [1], ${ }^{1}$ a method of measuring the thermal conductivity of solids was described in which the principal heat flow was parallel to the axis of a small circular disk-shaped specimen, but in which significant radial heat flows also occurred. Assuming axial symmetry, the authors used a least-mean-squares parabola to represent the measured radial temperature profile on each face of the specimen and assumed a linear longitudinal temperature distribution along the cylindrical surface of the specimen. Utilizing these boundary conditions, longitudinal temperature gradients at the cooler face of the specimen were determined by numerical solution of a finite difference equation using a digital computer. The thermal conductivity of the specimen was calculated from the average computed temperature gradient at the cooler surface and the measured heat flow leaving this surface.

A somewhat similar heat flow analysis is being used in the Heat Transfer Section of the National Bureau of Standards in conjunction with thermal conductivity measurements employing a guarded steam calorimeter for the measurement of heat flow through the central 3-in.-diam area of a 6-in.diam disk-shaped specimen [2]. The method is one of chiefly longitudinal heat flow, but corrections are occasionally necessary to account for radial heat flows. In order to effect such corrections, an exact analytical solution was obtained to the boundary value problem in which parabolic temperature distributions having axial symmetry are assumed on the two plane end surfaces, and a linear longitudinal temperature distribution is assumed on the convex surface, of a right circular cylinder.

Subsequent to the development of this analysis at NBS, a paper was published by Hoch et al. [3], in which a somewhat similar, although less general,

\footnotetext{
${ }^{1}$ Figures in brackets indicate the literature references at the end of this paper.
}

analytical solution was derived. In the latter paper, the heat conduction equation was solved for the case of a finite cylinder with the convex surface at a uniform temperature and the same axially symmetric parabolic temperature distribution on the two faces of the cylinder. The thermal conductivity of the specimen was calculated from the computed values of the temperature gradient at the center of the faces of the cylinder and of the heat flux radiated from these surfaces at the center, as determined by their temperature and emissivity.

In view of the general interest in this heat flow problem, it was decided to present, prior to formal publication of the paper [2] describing the NBS steam calorimeter apparatus, the mathematical analysis developed for it. The analysis given first treats the case of a right circular cylinder with arbitrary temperature boundary conditions, and then develops solutions for specific boundary conditions applicable to the determination of thermal conductivity.

\section{Mathematical Development}

Consider a homogeneous, isotropic, opaque, solid right cylinder of radius, $b$, and thickness, $l$. In general, the thermal conductivity of the cylinder material may vary with temperature. If so, the steady-state heat flow equation in cylindrical coordinates, assuming axial symmetry, is

$$
\vec{\nabla} \cdot(k \vec{\nabla} v)=\frac{1}{r} \frac{\partial}{\partial r}\left(k(v) r \frac{\partial v}{\partial r}\right)+\frac{\partial}{\partial z}\left(k(v) \frac{\partial v}{\partial z}\right)=0,
$$

where temperature above an arbitrary datum is denoted by the symbol $v$, the temperature-dependent thermal conductivity by $k(v)$, and the radial and longitudinal coordinates by $r$ and $z$, respectively. Equation (1) can be reduced to a simpler form by introduction of a new variable, $y$, defined by the relation

$$
y=\frac{1}{k^{*}} \int_{0}^{v} k\left(v^{\prime}\right) d v^{\prime},
$$


where $k^{*}$ is the value of $k(v)$ at $v=0 .^{2} \quad$ Utilizing (2), (1) reduces to $[4,5]$

$$
\nabla^{2} y=\frac{\partial^{2} y}{\partial r^{2}}+\frac{1}{r} \frac{\partial y}{\partial r}+\frac{\partial^{2} y}{\partial z^{2}}=0 .
$$

The variable, $y$, is essentially a potential whose gradient is proportional to the heat flux [6].

\subsection{General Boundary Conditions}

Assume the following boundary conditions:

$$
\begin{array}{lll}
z=0 & 0 \leq r \leq b & y=f(r), \\
z=l & 0 \leq r \leq b & y=g(r), \\
0<z<l & r=b & y=f(b)+[g(b)-f(b)] \frac{z}{l} \\
& & +h(z),
\end{array}
$$

where $f(r)$ and $g(r)$ are arbitrary potential distributions on the flat surfaces of the disk, and where, in order to insure continuity, we shall require that the function $h(z)$ vanishes at the flat surfaces of the disk, so that $h(0)=h(l)=0$. The solution is [7]: ${ }^{3}$

$$
\begin{array}{r}
y=f(b)+[g(b)-f(b)] \frac{z}{l}+\sum_{n=1}^{\infty} J_{0}\left(\alpha_{n} \frac{r}{b}\right) \\
\times\left\{A_{n} \sinh \left(\alpha_{n} \frac{z}{b}\right)+B_{n} \sinh \left(\alpha_{n} \frac{l-z}{b}\right)\right\} \\
+\sum_{k=1}^{\infty} C_{k} I_{0}\left(\frac{k \pi r}{l}\right) \sin \left(\frac{k \pi z}{l}\right),
\end{array}
$$

where $J_{0}$ and $I_{0}$ are, respectively, the ordinary and the modified Bessel functions of the first kind; the $\alpha_{n}$ 's are the positive roots of $J_{0}\left(\alpha_{n}\right)=0$. In order to satisfy the boundary conditions, the coefficients must be:

$$
A_{n}=\frac{2}{b^{2} \boldsymbol{J}_{1}^{2}\left(\alpha_{n}\right) \sinh \left(\alpha_{n} l / b\right)} \int_{0}^{b}\{g(r)-g(b)\} r \boldsymbol{J}_{0}\left(\alpha_{n} r / b\right) d r
$$

$B_{n}=\frac{2}{b^{2} J_{1}^{2}\left(\alpha_{n}\right) \sinh \left(\alpha_{n} l / b\right)} \int_{0}^{b}\{f(r)-f(b)\} r J_{0}\left(\alpha_{n} r / b\right) d r$

and

$$
C_{k}=\frac{2}{l I_{0}\left(\frac{k \pi b}{l}\right)} \int_{0}^{l} h(z) \sin \left(\frac{k \pi z}{l}\right) d z
$$

Equation (5) can be used to calculate the steadystate potential distribution in a finite cylinder corre-

2 This is a special case of the more general relation $d y=C k(v) d v$, where $C$ is an arbitrary constant.

3 This speeific problem is not handled by Carslaw and Jaeger; the form of solution and the necessary integrals are given in the chapter cited. sponding to arbitrary potential boundary conditions, $g(r), f(r)$, and $h(z)$. If the indicated integrations of $(6),(7)$, and (8) cannot be obtained analytically, values can be determined by numerical integration.

\subsection{Parabolic Boundary Conditions}

The boundary conditions used by Glaser et al. [1], Robinson et al. [2], and Hoch et al. [3] are all of the form

$$
\begin{aligned}
& f(r)=Y_{0}+E_{0} \frac{r^{2}}{b^{2}}, \\
& g(r)=Y_{1}+E_{1} \frac{r^{2}}{b^{2}},
\end{aligned}
$$

and

$$
h(z)=0,
$$

where $Y_{0}$ and $Y_{1}$ are the potentials (corresponding to $y$ ) at the centers of the faces of the disk, and $E_{0}$ and $E_{1}$ are the potential differences between the edge and the center of the disk at $z=0$ and $z=l$, respectively. With these boundary conditions, (5) becomes

$$
\begin{aligned}
y=\left(Y_{0}+E_{0}\right) & +\left(Y_{1}-Y_{0}+E_{1}-E_{0}\right) \frac{z}{l} \\
& -8 \sum_{n=1}^{\infty} \frac{J_{0}\left(\alpha_{n} r / b\right)}{\alpha_{n}^{3} J_{1}\left(\alpha_{n}\right) \sinh \left(\alpha_{n} l / b\right)} \\
& \times\left\{E_{1} \sinh \left(\alpha_{n} \frac{z}{b}\right)+E_{0} \sinh \left(\alpha_{n} \frac{l-z}{b}\right)\right\} .
\end{aligned}
$$

\section{Calculation of Thermal Conductivity}

The thermal conductivity of the disk is to be determined from the measured heat flow leaving a central portion of the disk of radius, $r=a$, and from the observed potential distributions on the surfaces of the disk. A mathematical expression giving the appropriate relationship between these quantities is derived by determining the total heat flow through a circle of radius $a$, at $z=0$ :

$$
Q=2 \pi \int_{0}^{a} r k(v)\left(\frac{\partial v}{\partial z}\right)_{z=0} d r=2 \pi k^{*} \int_{0}^{a} r\left(\frac{\partial y}{\partial z}\right)_{z=0} d r .
$$

Performing the indicated differentiation and integration on $(5)$,

$$
\begin{aligned}
Q=\pi a^{2} k^{*} & {\left[\frac{g(b)-f(b)}{l}+\frac{2}{a} \sum_{n=1}^{\infty} J_{1}\left(\alpha_{n} \frac{a}{b}\right)\right.} \\
\times & \left.\left\{A_{n}-B_{n} \cosh \left(\alpha_{n} \frac{l}{b}\right)\right\}+\frac{2}{a} \sum_{k=1}^{\infty} C_{k} I_{1}\left(\frac{k \pi a}{l}\right)\right] .
\end{aligned}
$$

Equation (12) can be rewritten in terms of the parabolic boundary conditions (9) discussed in section 2.2. If this is done, the heat flow through a circle of radius, $a$, becomes 


$$
Q=\pi a^{2} \frac{k^{*}}{l}\left[Y_{1}-Y_{0}+E_{1} \Psi_{1}-E_{0} \Psi_{0}\right]
$$

in which

$$
\Psi_{1}=1-16 \sum_{n=1}^{\infty} \frac{J_{1}\left(\alpha_{n} a / b\right)}{(a / b) \alpha_{n}^{3} J_{1}\left(\alpha_{n}\right)} \times \frac{(l / b)}{\sinh \left(\alpha_{n} l / b\right)}
$$

$$
\Psi_{0}=1-16 \sum_{n=1}^{\infty} \frac{J_{1}\left(\alpha_{n} a / b\right)}{(a / b) \alpha_{n}^{3} J_{1}\left(\alpha_{n}\right)} \times \frac{(l / b)}{\tanh \left(\alpha_{n} l / b\right)}
$$

are factors which depend only on the geometry of the disk and on the fraction of the disk from which the heat flow is measured. If all of the other quantities are known, eq (13) can be used to compute the thermal conductivity, $k^{*}$. In order to compute the values of the potential, $y$, for use in eq (13), some assumption must be made regarding the temperaturedependence of the thermal conductivity of the disk (see eq (2)). This is discussed in section 4.

In the special case, $l / b=0,(14)$ and (15) reduce to

$$
\Psi_{1}=\Psi_{0}=1-16 \sum_{n=1}^{\infty} \frac{J_{1}\left(\alpha_{n} a / b\right)}{(a / b) \alpha_{n}^{4} J_{1}\left(\alpha_{n}\right)}=\frac{1}{2}\left(\frac{a}{b}\right)^{2} .
$$

\begin{tabular}{|c|c|c|c|c|c|c|c|c|c|c|c|c|}
\hline$a / b$ & 0.00 & 0.10 & 0.20 & 0.30 & 0.40 & 0.50 & 0.60 & 0.70 & 0.80 & 0.90 & 1.00 & $a / b$ \\
\hline $\begin{array}{l}0.0 \\
0.1 \\
0.2 \\
0.3 \\
0.4\end{array}$ & $\begin{array}{r}0.00000 \\
.00667 \\
.02667 \\
.05998 \\
.10632\end{array}$ & $\begin{array}{r}0.00500 \\
.01167 \\
.03167 \\
.06498 \\
.11129\end{array}$ & $\begin{array}{r}0.02000 \\
.02667 \\
.04667 \\
.07997 \\
.12620\end{array}$ & $\begin{array}{r}0.04500 \\
.05167 \\
.07167 \\
.10495 \\
.15102\end{array}$ & $\begin{array}{r}0.08000 \\
.08667 \\
.10667 \\
.13991 \\
.18567\end{array}$ & $\begin{array}{r}0.12500 \\
.13167 \\
.15166 \\
.18481 \\
.23005\end{array}$ & $\begin{array}{r}0.18000 \\
.18667 \\
.20665 \\
.23958 \\
.28392\end{array}$ & $\begin{array}{r}0.24500 \\
.25167 \\
.27161 \\
.30404 \\
.34686\end{array}$ & $\begin{array}{r}0.32000 \\
.32667 \\
.34643 \\
.37778 \\
.41806\end{array}$ & $\begin{array}{r}0.40500 \\
.41164 \\
.43072 \\
.45980 \\
.49616\end{array}$ & $\begin{array}{r}0.50000 \\
.50621 \\
.52307 \\
.54809 \\
.57896\end{array}$ & $\begin{array}{l}0.0 \\
0.1 \\
0.2 \\
0.3 \\
0.4\end{array}$ \\
\hline $\begin{array}{l}0.5 \\
0.6 \\
0.7 \\
0.8 \\
0.9\end{array}$ & $\begin{array}{l}.16434 \\
.23135 \\
.30380 \\
.37813 \\
.45129\end{array}$ & $\begin{array}{l}.16923 \\
.23605 \\
.30822 \\
.38221 \\
.45497\end{array}$ & $\begin{array}{l}.18385 \\
.25011 \\
.32145 \\
.39438 \\
.46596\end{array}$ & $\begin{array}{l}.20815 \\
.27341 \\
.34330 \\
.41444 \\
.48404\end{array}$ & $\begin{array}{l}.24197 \\
.30571 \\
.37347 \\
.44204 \\
.50885\end{array}$ & $\begin{array}{l}.28505 \\
.34664 \\
.41149 \\
.47667 \\
.53986\end{array}$ & $\begin{array}{l}.33699 \\
.39561 \\
.45670 \\
.51764 \\
.57638\end{array}$ & $\begin{array}{l}.39712 \\
.45181 \\
.50820 \\
.56402 \\
.61755\end{array}$ & $\begin{array}{l}.46439 \\
.51408 \\
.56481 \\
.61470 \\
.66232\end{array}$ & $\begin{array}{l}.53726 \\
.58086 \\
.62507 \\
.66833 \\
.70951\end{array}$ & $\begin{array}{l}.61362 \\
.65024 \\
.68726 \\
.72344 \\
.75783\end{array}$ & $\begin{array}{l}0.5 \\
0.6 \\
0.7 \\
0.8 \\
0.9\end{array}$ \\
\hline $\begin{array}{l}1.0 \\
1.2 \\
1.4 \\
1.6 \\
1.8\end{array}$ & $\begin{array}{l}.52097 \\
.64440 \\
.74323 \\
.81842 \\
.87364\end{array}$ & $\begin{array}{l}.52424 \\
.64690 \\
.74505 \\
.81971 \\
.87454\end{array}$ & $\begin{array}{l}.53401 \\
.65431 \\
.75047 \\
.82357 \\
.87724\end{array}$ & $\begin{array}{l}.55004 \\
.66646 \\
.75935 \\
.82989 \\
.88165\end{array}$ & $\begin{array}{l}.57200 \\
.68305 \\
.77144 \\
.83849 \\
.88765\end{array}$ & $\begin{array}{l}.59937 \\
.70365 \\
.78643 \\
.84913 \\
.89507\end{array}$ & $\begin{array}{r}.63149 \\
.72773 \\
.80390 \\
.86152 \\
.90370\end{array}$ & $\begin{array}{l}.66758 \\
.75466 \\
.82340 \\
.87533 \\
.91332\end{array}$ & $\begin{array}{l}.70670 \\
.78372 \\
.84439 \\
.89017 \\
.92365\end{array}$ & $\begin{array}{l}.74781 \\
.81414 \\
.86632 \\
.90567 \\
.93443\end{array}$ & $\begin{array}{l}.78979 \\
.84512 \\
.88861 \\
.92140 \\
.94537\end{array}$ & $\begin{array}{l}1.0 \\
1.2 \\
1.4 \\
1.6 \\
1.8\end{array}$ \\
\hline $\begin{array}{l}2.0 \\
2.2 \\
2.4 \\
2.6 \\
2.8\end{array}$ & $\begin{array}{l}.91317 \\
.94094 \\
.96017 \\
.97332 \\
.98224\end{array}$ & $\begin{array}{l}.91379 \\
.94137 \\
.96045 \\
.97351 \\
.98237\end{array}$ & $\begin{array}{r}.91565 \\
.94263 \\
.96131 \\
.97409 \\
.98275\end{array}$ & $\begin{array}{l}.91869 \\
.94470 \\
.96270 \\
.97502 \\
.98337\end{array}$ & $\begin{array}{l}.92281 \\
.94751 \\
.96460 \\
.97629 \\
.98422\end{array}$ & $\begin{array}{l}.92792 \\
.95098 \\
.96694 \\
.97786 \\
.98526\end{array}$ & $\begin{array}{l}.93386 \\
.95502 \\
.96967 \\
.97969 \\
.98648\end{array}$ & $\begin{array}{l}.94047 \\
.95952 \\
.97270 \\
.98172 \\
.98783\end{array}$ & $\begin{array}{l}.94757 \\
.96435 \\
.97596 \\
.98390 \\
.98928\end{array}$ & $\begin{array}{l}.95497 \\
.96938 \\
.97935 \\
.98617 \\
.99080\end{array}$ & $\begin{array}{r}.96248 \\
.97449 \\
.98280 \\
.98848 \\
.99233\end{array}$ & $\begin{array}{l}2.0 \\
2.2 \\
2.4 \\
2.6 \\
2.8\end{array}$ \\
\hline $\begin{array}{l}3.0 \\
3.5 \\
4.0 \\
4.5 \\
5.0\end{array}$ & $\begin{array}{r}.98824 \\
.99588 \\
.99858 \\
.99952 \\
.99984\end{array}$ & $\begin{array}{l}.98832 \\
.99591 \\
.99859 \\
.99952 \\
.99984\end{array}$ & $\begin{array}{l}.98857 \\
.99599 \\
.99862 \\
.99954 \\
.99984\end{array}$ & $\begin{array}{r}.98898 \\
.99614 \\
.99867 \\
.99955 \\
.99985\end{array}$ & $\begin{array}{l}.98954 \\
.99633 \\
.99874 \\
.99957 \\
.99986\end{array}$ & $\begin{array}{l}.99024 \\
.99658 \\
.99882 \\
.99960 \\
.99987\end{array}$ & $\begin{array}{l}.99104 \\
.99686 \\
.99892 \\
.99964 \\
.99988\end{array}$ & $\begin{array}{r}99194 \\
.99717 \\
.99903 \\
.99967 \\
.99989\end{array}$ & $\begin{array}{l}.99290 \\
.99751 \\
.99915 \\
.99971 \\
.99990\end{array}$ & $\begin{array}{r}.99390 \\
99786 \\
.99927 \\
.99975 \\
.99992\end{array}$ & $\begin{array}{r}.99492 \\
.99822 \\
.99939 \\
.99979 \\
.99993\end{array}$ & $\begin{array}{l}3.0 \\
3.5 \\
4.0 \\
4.5 \\
5.0\end{array}$ \\
\hline & 0.00 & 0.10 & 0.20 & 0.30 & 0.40 & 0.50 & 0.60 & 0.70 & 0.80 & 0.90 & 1.00 & \\
\hline
\end{tabular}

In the special case, $a / b=0$, used by Hoch et al. [3],

\begin{tabular}{|c|c|c|c|c|c|c|c|c|c|c|c|c|}
\hline$a / b$ & 0.00 & 0.10 & 0.20 & 0.30 & 0.40 & 0.50 & 0.60 & 0.70 & 0.80 & 0.90 & 1.00 & \\
\hline $\begin{array}{l}0.0 \\
0.1 \\
0.2 \\
0.3 \\
0.4\end{array}$ & $\begin{array}{r}0.00000 \\
-.01332 \\
-.05332 \\
-.11997 \\
-.21297\end{array}$ & $\begin{array}{r}0.00500 \\
-.00832 \\
-.04832 \\
-.11497 \\
-.20794\end{array}$ & $\begin{array}{r}0.02000 \\
.00667 \\
-.03332 \\
-.09996 \\
-.19285\end{array}$ & $\begin{array}{r}0.04500 \\
.03167 \\
-.00832 \\
-.07494 \\
-.16767\end{array}$ & $\begin{array}{r}0.08000 \\
.06667 \\
.02667 \\
-.03989 \\
-.13232\end{array}$ & $\begin{array}{r}0.12500 \\
.11167 \\
.07168 \\
.00520 \\
-.08670\end{array}$ & $\begin{array}{r}0.18000 \\
.16667 \\
.12669 \\
.06043 \\
-.03054\end{array}$ & $\begin{array}{r}0.24500 \\
.23167 \\
.19173 \\
.12597 \\
.03661\end{array}$ & $\begin{array}{r}0.32000 \\
.30667 \\
.26691 \\
.20230 \\
.11577\end{array}$ & $\begin{array}{r}0.40500 \\
.39170 \\
.35267 \\
.29070 \\
.20918\end{array}$ & $\begin{array}{r}0.50000 \\
.48728 \\
.45149 \\
.39601 \\
.32401\end{array}$ & $\begin{array}{l}0.0 \\
0.1 \\
0.2 \\
0.3 \\
0.4\end{array}$ \\
\hline $\begin{array}{l}0.5 \\
0.6 \\
0.7 \\
0.8 \\
0.9\end{array}$ & $\begin{array}{l}-.33099 \\
-.47129 \\
-.63026 \\
-.80408 \\
-.98928\end{array}$ & $\begin{array}{r}-.32587 \\
-.46600 \\
-.62467 \\
-.79811 \\
-.98285\end{array}$ & $\begin{array}{l}-.31050 \\
-.45004 \\
-.60783 \\
-.78009 \\
-.96344\end{array}$ & $\begin{array}{r}-.28479 \\
-.42330 \\
-.57954 \\
-.74979 \\
-.93074\end{array}$ & $\begin{array}{l}-.24859 \\
-.38552 \\
-.53942 \\
-.70670 \\
-.88417\end{array}$ & $\begin{array}{r}-.20163 \\
-.33624 \\
-.48688 \\
-.65008 \\
-.82283\end{array}$ & $\begin{array}{l}-.14343 \\
-.27476 \\
-.42095 \\
-.57874 \\
-.74531\end{array}$ & $\begin{array}{l}-.07317 \\
-.19987 \\
-.34009 \\
-.49081 \\
-.64945\end{array}$ & $\begin{array}{r}.01071 \\
-.10948 \\
-.24168 \\
-.38317 \\
-.53165\end{array}$ & $\begin{array}{r}.11143 \\
.00054 \\
-.12072 \\
-.24998 \\
-.38525\end{array}$ & $\begin{array}{r}.23839 \\
.14178 \\
.03652 \\
-.07542 \\
-.19237\end{array}$ & $\begin{array}{l}0.5 \\
0.6 \\
0.7 \\
0.8 \\
0.9\end{array}$ \\
\hline $\begin{array}{l}1.0 \\
1.2 \\
1.4 \\
1.6 \\
1.8\end{array}$ & $\begin{array}{l}-1.18294 \\
-1.58699 \\
-2.00374 \\
-2.42657 \\
-2.85220\end{array}$ & $\begin{array}{l}-1.17599 \\
-1.57889 \\
-1.99439 \\
-2.41593 \\
-2.84025\end{array}$ & $\begin{array}{l}-1.15500 \\
-1.55439 \\
-1.96613 \\
-2.38376 \\
-2.80412\end{array}$ & $\begin{array}{l}-1.11962 \\
-1.51307 \\
-1.91842 \\
-2.32946 \\
-2.74312\end{array}$ & $\begin{array}{l}-1.06917 \\
-1.45408 \\
-1.85029 \\
-2.25189 \\
-2.65598\end{array}$ & $\begin{array}{l}-1.00262 \\
-1.37613 \\
-1.76019 \\
-2.14929 \\
-2.54072\end{array}$ & $\begin{array}{l}-.91837 \\
-1.27724 \\
-1.64581 \\
-2.01900 \\
-2.39433\end{array}$ & $\begin{array}{r}-.81394 \\
-1.15440 \\
-1.50358 \\
-1.85694 \\
-2.21221\end{array}$ & $\begin{array}{l}-.68528 \\
-1.00267 \\
-1.32776 \\
-1.65651 \\
-1.98694\end{array}$ & $\begin{array}{r}-.52496 \\
-.81307 \\
-1.10776 \\
-1.40562 \\
-1.70493\end{array}$ & $\begin{array}{r}-.31301 \\
-.56155 \\
-.81558 \\
-1.07223 \\
-1.33010\end{array}$ & $\begin{array}{l}1.0 \\
1.2 \\
1.4 \\
1.6 \\
1.8\end{array}$ \\
\hline $\begin{array}{l}2.0 \\
2.2 \\
2.4 \\
2.6 \\
2.8\end{array}$ & $\begin{array}{l}-3.27905 \\
-3.70648 \\
-4.13414 \\
-4.56191 \\
-4.98972\end{array}$ & $\begin{array}{l}-3.26578 \\
-3.69189 \\
-4.11823 \\
-4.54467 \\
-4.97115\end{array}$ & $\begin{array}{l}-3.22566 \\
-3.64776 \\
-4.07010 \\
-4.49253 \\
-4.91500\end{array}$ & $\begin{array}{l}-3.15793 \\
-3.57328 \\
-3.98885 \\
-4.40451 \\
-4.82021\end{array}$ & $\begin{array}{l}-3.06116 \\
-3.46686 \\
-3.87276 \\
-4.27876 \\
-4.68479\end{array}$ & $\begin{array}{l}-2.93319 \\
-3.32608 \\
-3.71920 \\
-4.11240 \\
-4.50564\end{array}$ & $\begin{array}{l}-2.77061 \\
-3.14727 \\
-3.52415 \\
-3.90111 \\
-4.27809\end{array}$ & $\begin{array}{l}-2.56834 \\
-2.92485 \\
-3.28149 \\
-3.63823 \\
-3.99500\end{array}$ & $\begin{array}{l}-2.31814 \\
-2.64967 \\
-2.98133 \\
-3.31304 \\
-3.64479\end{array}$ & $\begin{array}{l}-2.00488 \\
-2.30512 \\
-2.60549 \\
-2.90590 \\
-3.20632\end{array}$ & $\begin{array}{l}-1.58850 \\
-1.84715 \\
-2.10589 \\
-2.36468 \\
-2.62349\end{array}$ & $\begin{array}{l}2.0 \\
2.2 \\
2.4 \\
2.6 \\
2.8\end{array}$ \\
\hline \multirow[t]{2}{*}{$\begin{array}{l}3.0 \\
3.5 \\
4.0 \\
4.5 \\
5.0\end{array}$} & $\begin{array}{l}-5.41754 \\
-6.48713 \\
-7.55668 \\
-8.62628 \\
-9.69588\end{array}$ & $\begin{array}{l}-5.39766 \\
-6.46393 \\
-7.53016 \\
-8.59644 \\
-9.66273\end{array}$ & $\begin{array}{l}-5.33749 \\
-6.39374 \\
-7.44994 \\
-8.50620 \\
-9.56245\end{array}$ & $\begin{array}{l}-5.23593 \\
-6.27526 \\
-7.31453 \\
-8.35386 \\
-9.39319\end{array}$ & $\begin{array}{l}-5.09084 \\
-6.10598 \\
-7.12107 \\
-8.13622 \\
-9.15136\end{array}$ & $\begin{array}{l}-4.89889 \\
-5.88204 \\
-6.86520 \\
-7.84830 \\
-8.83146\end{array}$ & $\begin{array}{l}-4.65509 \\
-5.59761 \\
-6.54013 \\
-7.48260 \\
-8.42512\end{array}$ & $\begin{array}{l}-4.35178 \\
-5.24374 \\
-6.13572 \\
-7.02763 \\
-7.91960\end{array}$ & $\begin{array}{l}-3.97656 \\
-4.80599 \\
-5.63542 \\
-6.46486 \\
-7.29424\end{array}$ & $\begin{array}{l}-3.50676 \\
-4.25790 \\
-5.00903 \\
-5.76017 \\
-6.51130\end{array}$ & $\begin{array}{l}-2.88230 \\
-3.52934 \\
-4.17639 \\
-4.82345 \\
-5.47050\end{array}$ & $\begin{array}{l}3.0 \\
3.5 \\
4.0 \\
4.5 \\
5.0\end{array}$ \\
\hline & 0.00 & 0.10 & 0.30 & 0.30 & 0.40 & 0.50 & 0.60 & 0.70 & 0.80 & 0.90 & 1. 00 & \\
\hline
\end{tabular}

TABLE 1. The coefficient $\Psi_{1}$ as a function of $l / b$ and $a / b$ for parabolic boundary conditions

TABLE 2. The coefficient $\Psi_{0}$ as a function of $l / b$ and $a / b$ for parabolic boundary conditions 


$$
\Psi_{1}=1-8 \sum_{n=1}^{\infty} \frac{1}{\alpha_{n}^{2} J_{1}\left(\alpha_{n}\right)} \times \frac{(l / b)}{\sinh \left(\alpha_{n} l / b\right)}
$$

and

$$
\Psi_{0}=1-8 \sum_{n=1}^{\infty} \frac{1}{\alpha_{n}^{2} J_{1}\left(\alpha_{n}\right)} \times \frac{(l / b)}{\tanh \left(\alpha_{n} l / b\right)} .
$$

For large values of $l / b$,

and

$$
\Psi_{1} \rightarrow 1
$$

where

$$
\Psi_{0} \rightarrow 1-(l / b) \Phi
$$

$$
\Phi=16 \sum_{n=1}^{\infty} \frac{J_{1}\left(\alpha_{n} a / b\right)}{(a / b) \alpha_{n}^{3} J_{1}\left(\alpha_{n}\right)}
$$

is a function of $a / b$ only.

Using a high-speed digital computer, numerical values for $\Psi_{1}$ and $\Psi_{0}$ have been calculated for a range of values of $a / b$ and $l / b$ and are given in tables 1 and 2 . Representative values are plotted in figure 1 . The series for $\Psi_{1}$ is rapidly convergent, due to the quantity, $\sinh \left(\alpha_{n} l / b\right)$, which appears in the denominator. The series for $\Psi_{0}$, however, converges rather slowly and it was necessary to sum at least the first one thousand terms of this series in order to obtain the number of significant figures given in table 2 .

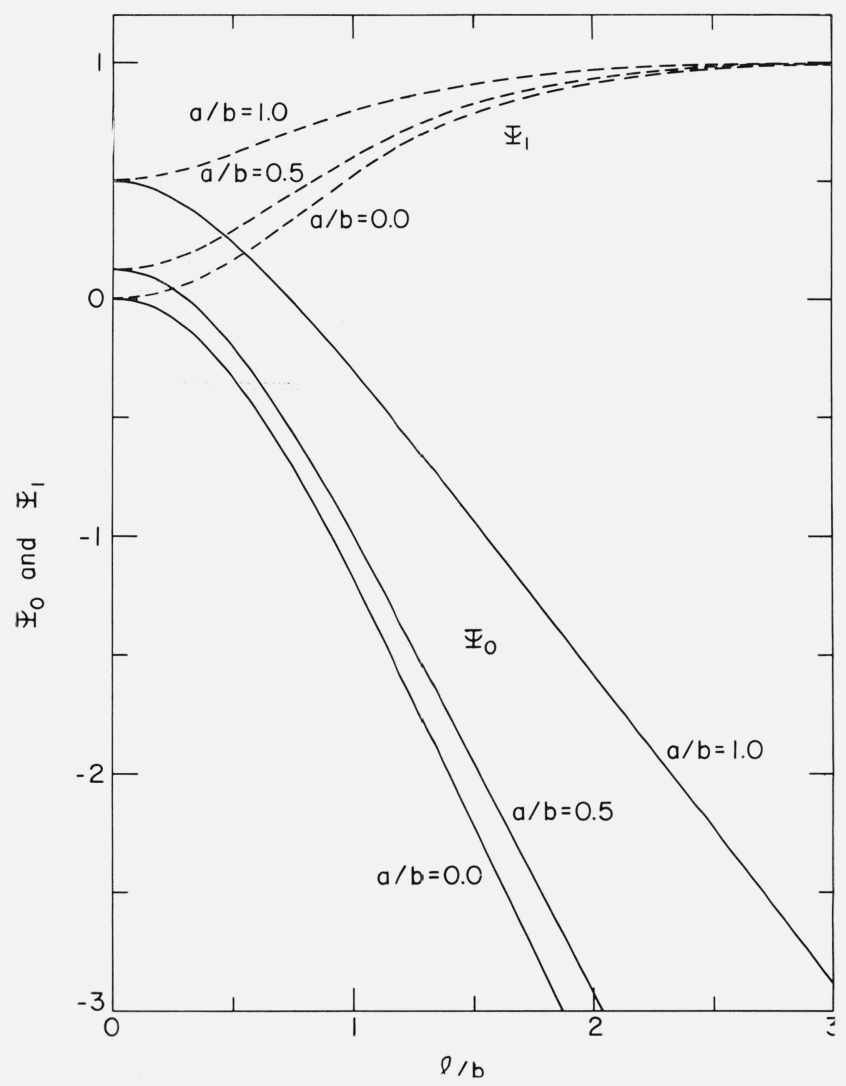

FIgURE 1. The coefficients $\Psi_{0}$ and $\Psi_{1}$ for the case of parabolic boundary conditions; solid lines, $\Psi_{0}$; dashed lines, $\Psi_{1}$.
For values of $l / b$ larger than those given in tables 1 and $2, \Psi_{1}$ is substantially unity and $\Psi_{0}$ may be computed using (20) and the values of $\Phi$ given in table 3.

TABLE 3. The function $\Phi$ which is used for computing values of $\Psi_{0}$ corresponding to large $l / b$

\begin{tabular}{c|c}
\hline \hline$a / b$ & $\Phi$ \\
\hline & \\
\hline 0.0 & 2.13918 \\
0.1 & 2.13255 \\
0.2 & 2.11249 \\
0.3 & 2.07864 \\
0.4 & 2.03028 \\
0.5 & 1.99630 \\
0.6 & 1.88502 \\
0.7 & 1.78393 \\
0.8 & 1.65885 \\
0.9 & 1.50226 \\
1.0 & 1.29410 \\
\hline
\end{tabular}

\section{Effective Mean Temperature}

The thermal conductivity of the disk at $v=0$ can be computed from (12) for the general case or from (13) for the case of parabolic boundary conditions. The variable, $v$, is the temperature measured from an arbitrary reference temperature, say $T^{*}$. Thus the conductivity obtained, $k^{*}$, corresponds to the reference temperature $T^{*}$. The variable, $y$, as mentioned previously, depends on the temperaturedependence of the thermal conductivity of the disk. Two particular cases of interest are discussed here.

\subsection{Thermal Conductivity Having Linear Temperature-Dependence}

For many materials the thermal conductivity can be assumed to vary linearly with temperature over a moderate temperature range, such that

then, from (2),

$$
k(v)=k^{*}[1+\beta v] ;
$$

$$
y=v+\frac{\beta}{2} v^{2} .
$$

The boundary conditions must be written in terms of $y$ and then substituted into the appropriate equations.

For the case of parabolic boundary conditions, the following relations hold:

$$
\begin{aligned}
Y_{0} & =V_{0}+\frac{\beta}{2} V_{0}^{2} & Y_{1} & =V_{1}+\frac{\beta}{2} V_{1}^{2} \\
E_{0} & =D_{0}+\frac{\beta}{2}\left(D_{0}^{2}+2 D_{0} V_{0}\right) & E_{1} & =D_{1}+\frac{\beta}{2}\left(D_{1}^{2}+2 D_{1} V_{1}\right),
\end{aligned}
$$

where $V_{0}=T_{0}-T^{*}$ and $V_{1}=T_{1}-T^{*}, T_{0}$ and $T_{1}$ being the temperatures at the center of the disk at $z=0$ and $z=l$, respectively, and $D_{0}$ and $D_{1}$ are the temperature differences between the edge and the center of the disk at $z=0$ and $z=l$, respectively. 
In order to compute the thermal conductivity of the disk, eqs (24) and (25) must be substituted into (13). The resultant expression, however, involves $\beta$, the temperature coefficient of the thermal conductivity, a quantity which may not be known. This dependence can be eliminated by proper choice of the reference temperature, $T^{*}$. If $T^{*}$ is defined as

$$
T^{*}=\frac{T_{1}+T_{0}}{2}+\frac{D_{1} \Psi_{1}\left(T_{1}-T_{0}+D_{1}\right)+D_{0} \Psi_{0}\left(T_{1}-T_{0}-D_{0}\right)}{2\left[T_{1}-T_{0}+D_{1} \Psi_{1}-D_{0} \Psi_{0}\right]},
$$

then eq (13) reduces to

$$
Q=\pi a^{2} \frac{k^{*}}{l}\left[T_{1}-T_{0}+D_{1} \Psi_{1}-D_{0} \Psi_{0}\right]
$$

which is the expression that would be obtained for the case of a specimen having constant thermal conductivity, $k^{*}$. For the special case in which there is no radial heat flow, $D_{1}=D_{0}=0$, and (26) reduces to $T^{*}=\left(T_{1}+T_{0}\right) / 2[8]$.

\subsection{Thermal Resistivity Having Linear Temperature-Dependence}

For many crystalline dielectric solids, the thermal resistivity, i.e., the reciprocal of thermal conductivity, varies substantially linearly with temperature over a considerable temperature range. In this case, the thermal conductivity can be written as

then, from (2),

$$
k(v)=\frac{k^{*}}{1+\gamma v} ;
$$

$$
y=\frac{1}{\gamma} \ln (1+\gamma v) \text {. }
$$

The relation between $y$ and $v$ can be better seen by expanding (29) in series form,

$$
y=v\left(1-\frac{\gamma v}{2}+\frac{(\gamma v)^{2}}{3}-\ldots\right)
$$

provided $|\gamma v|<1$.

In the present case the coefficient $\gamma$ is not so amenable to elimination by choice of a particular reference temperature as was the coefficient $\beta$ in section 4.1. In computing thermal conductivity values for a material whose thermal conductivity is expected to have a temperature dependence such as that in (28), one may first assume that $|\gamma v|$ is suffciently small to permit terminating eq (30) after the second term of the series; i.e., $y=v-\gamma v^{2} / 2$. Comparison of this expression with (23) shows that the assumption that $|\gamma v|$ is small is equivalent to assuming a linear temperature dependence for the thermal conductivity. Thus one may use (26) and (27) to compute a mean temperature and the approximate thermal conductivity at that temperature. The first approximations to the thermal conductivity thus obtained for several tests at different mean temperatures can be used to compute values of the coefficient $\gamma$ which then can be used in (29) or (30) to obtain values of $y$, which can in turn be used in (13) to obtain more refined values for thermal conductivity. The resultant value of $k^{*}$ can be used to obtain better values of $\gamma$, etc. The convergence is quite rapid in most practical cases, so that only one or two iterations will normally be required.

\section{Examples}

In order to illustrate the use of the mathematical developments presented in this paper, we now shall cite specific examples in which the factors $\Psi_{1}$ and $\Psi_{0}$ given in section 3 for parabolic boundary conditions are utilized to compute thermal conductivity values from measured temperatures and a measured heat flow. One example will be given for each of the three methods mentioned in section $1[1,2,3]$.

\subsection{Method of Glaser et al.}

In the method described by Glaser et al. [1], the entire heat flow leaving the colder flat surface of the disk-shaped specimen is determined, i.e., in the nomenclature of the present paper, $a / b=1.0$. We postulate the following data as having been acquired experimentally: ${ }^{4}$

$$
\begin{array}{rr}
a=b=0.476 \mathrm{~cm} & l=0.160 \mathrm{~cm} \\
Q=9.60 \mathrm{~W} & \\
T_{0}=1319{ }^{\circ} \mathrm{C} & D_{0}=-218 \mathrm{deg} \\
T_{1}=1536^{\circ} \mathrm{C} & D_{1}=-338 \mathrm{deg}
\end{array}
$$

Interpolation of table 1 and 2 for the case $a / b=1.0$ and $l / b=0.336$ yields,

$$
\Psi_{1}=0.559 \quad \Psi_{0}=0.372 .
$$

Assuming linear temperature dependence, the thermal conductivity is computed using (27). Substituting the values given above for the various parameters and solving for thermal conductivity,

$$
k^{*}=0.0198 \mathrm{~W} / \mathrm{cm} \mathrm{deg} \text {. }
$$

The mean temperature is computed from (26) as:

$$
T^{*}=1370{ }^{\circ} \mathrm{C} \text {. }
$$

It should be remembered that, for a given specimen size and shape, the factors $\Psi_{1}$ and $\Psi_{0}$ remain constant. The only further information needed to compute thermal conductivity values for a given specimen is the heat flow and four temperatures (in effect). Thus the procedure described by Glaser et al. [1], in which each thermal conductivity value was obtained by numerical solution of a finite difference equation on a high-speed digital computer, can now be replaced by a fairly simple hand calculation using the values of $\Psi_{1}$ and $\Psi_{0}$ tabulated in this paper.

4 This is an actual set of data which was made available through the courtesy of P. E. Glaser of Arthur D. Little, Inc. 


\subsection{Method of Robinson et al.}

In the NBS steam calorimeter method [2], the total heat flow through only a central section of the specimen is measured. Let us assume that the thermal resistivity, rather than the thermal conductivity, of the specimen exhibits a linear temperature dependence; i.e., the thermal conductivity is of the form given in (28). We postulate the following data as having been acquired experimentally:

$$
\begin{aligned}
& a=3.81 \mathrm{~cm} \quad b=7.62 \mathrm{~cm} \quad l=2.29 \mathrm{~cm} \\
& Q=542 \mathrm{~W} \\
& T_{0}=540{ }^{\circ} \mathrm{C} \quad D_{0}=-20 \mathrm{deg} \\
& T_{1}=980{ }^{\circ} \mathrm{C} \quad D_{1}=-40 \mathrm{deg}
\end{aligned}
$$

For the case $a / b=0.5$ and $l / b=0.3$, table 1 and 2 yield

$$
\Psi_{1}=0.18481 \quad \Psi_{0}=0.00520 .
$$

Substitution into (26) and (27) yields

$$
k^{*}=0.0629 \mathrm{~W} / \mathrm{cm} \mathrm{deg} \text { at } T^{*}=756.5{ }^{\circ} \mathrm{C}
$$

as a first approximation to the thermal conductivity at this temperature. If similar sets of data at other temperature levels are analyzed in this manner, the resultant thermal conductivity values can be used to compute values for $\gamma$, the thermal resistivity temperature coefficient. Let us assume that this has been done and that a value of $\gamma=9.0 \times 10^{-4} \mathrm{deg}^{-1}$ at $757{ }^{\circ} \mathrm{C}$ was obtained. Using $T^{*}=757{ }^{\circ} \mathrm{C}$ as a reference temperature,

$$
V_{0}=-217 \mathrm{deg} \quad V_{1}=223 \mathrm{deg} .
$$

Substitution of these values for $V_{0}$ and $V_{1}$ and the above-mentioned values for $D_{0}, D_{1}$, and $\gamma$ into (29) yields

$$
\begin{array}{ll}
Y_{0}=-241.4 \mathrm{deg} & E_{0}=-25.1 \mathrm{deg} \\
Y_{1}=203.2 \mathrm{deg} & E_{1}=-33.8 \mathrm{deg}
\end{array}
$$

Substitution of these values of $Y_{0}, Y_{1}, E_{0}$, and $E_{1}$ into (13) yields

$$
k^{*}=0.0621 \mathrm{~W} / \mathrm{cm} \mathrm{deg} \text { at } T^{*}=757^{\circ} \mathrm{C}
$$

as the improved value for the thermal conductivity. If thought necessary, the improved values for the thermal conductivity can be used to compute an improved value for $\gamma$ for further refinement of the final thermal conductivity values.

\subsection{Method of Hoch et al.}

In the method described by Hoch et al. [3], the heat flux from the center of the flat surfaces of the disk is calculated from the temperature at that point and the total hemispherical emittance of the specimen, using the Stefan-Boltzmann radiation law. Since Hoch et al. derived an analytical solution for their case which is quite similar to that developed in the present paper for more general conditions, it is of interest to compare these solutions. Hoch et al. define a characteristic constant, $K_{0}$, which is given by ${ }^{5}$

$$
K_{0}=2 \sum_{n=1}^{\infty} \frac{\tanh \left(\alpha_{n} l / 2 b\right)}{\alpha_{n}^{2} J_{1}\left(\alpha_{n}\right)}
$$

where the notation has been changed to conform with that of the present paper.

With the simplified boundary conditions assumed by Hoch et al. $\left(Y_{1}=Y_{0}, E_{1}=E_{0}\right)$, the heat flux at the center of the surface of the disk is given by

$$
k^{*}\left(\frac{\partial y}{\partial z}\right)_{\substack{r=0 \\ z=0}}=\frac{k^{*}}{l} E_{0}\left[\Psi_{1}-\Psi_{0}\right] .
$$

This expression is analogous to (13), except that it refers to the heat flux at a point rather than to the total heat flow through a circular area. For the case $a / b=0$, with parabolic boundary conditions, the factors $\Psi_{1}$ and $\Psi_{0}$ are given by (17) and (18); the quantity $\left[\Psi_{1}-\Psi_{0}\right]$ becomes

$$
\begin{aligned}
{\left[\Psi_{1}-\Psi_{0}\right]=8 \sum_{n=1}^{\infty} \frac{l / b}{\alpha_{n}^{2} J_{1}\left(\alpha_{n}\right)}\left[\frac{1}{\tanh \left(\alpha_{n} l / b\right)}\right.} & \\
& \left.-\frac{1}{\sinh \left(\alpha_{n} l / b\right)}\right],
\end{aligned}
$$

which reduces to

$$
\left[\Psi_{1}-\Psi_{0}\right]=8(l / b) \sum_{n=1}^{\infty} \frac{\tanh \left(\alpha_{n} l / 2 b\right)}{\alpha_{n}^{2} J_{1}\left(\alpha_{n}\right)} .
$$

Comparison of (31) and (34) yields

$$
K_{0}=\frac{b}{4 l}\left[\Psi_{1}-\Psi_{0}\right]
$$

Since Hoch et al. included a numerical example in their paper, it is needless to present one here. Values for $K_{0}$ can be computed using eq (35) and the appropriate values of $\Psi_{1}$ and $\Psi_{0}$ from the first column in tables 1 and 2. Hoch and Nitti [9] more recently have published an expanded version of their previous paper [3] in which they tabulate values of $K_{0}$ for several specimen shapes.

\section{Discussion}

For the case of parabolic radial potential distributions on the flat surfaces of the disk and a linear longitudinal potential distribution on the convex surface, the equations and tabulated coefficients given in this paper permit rapid hand computation of thermal conductivity values from experimental data. If boundary conditions other than those of eq (9) are required or indicated, thermal conductivity values should be computed from (12), rather than (13), with the appropriate coefficients being given

${ }^{5}$ Cf. equation (12), page 514, reference [3]; in the present paper this equation has been reduced, by means of recurrence relations, to a simpler form than that given originally by Hoch et al. 
by (6), (7), and (8). Equation (12) is completely rigorous for the axially-symmetric boundary conditions (4a), (4b), and (4c). Proof of adequate compliance with these boundary conditions would appear to be indicated for any given test method. Hoch et al., [3, 9] have discussed the influence of one particular type of boundary condition, other than linear, on the convex surface of the disk. Other boundary conditions can be handled by evaluation of the appropriate integrals given in this paper.

The author thanks B. A. Peavy for checking the mathematical analysis given in this paper.

\section{References}

[1] P. E. Glaser, S. Merra, W. K. Sepetoski, D. F. Comstock, and A. G. Emslie, Radiation imaging technique for thermal conductivity measurement above $1000{ }^{\circ} \mathrm{C}$, Rev. Sci. Instr. 33, 57 (1962).

[2] H. E. Robinson, D. R. Flynn, and D. A. Didion, A steam calorimeter apparatus for measuring the thermal conductivity of refractories (to be published).
[3] M. Hoch, D. A. Nitti, C. F. Gottschlich, and P. E. Blackburn, New method for the determination of thermal conductivities between $1000^{\circ}$ and $3000^{\circ} \mathrm{C}$, in Progress in International Research on Thermodynamic and Transport Properties, p. 512 (ASME, Academic Press, New York, 1962).

[4] M. S. Van Dusen, Note on the theory of heat conduction, NBS J. Res. 4, 753 (1930) RP178.

[5] H. S. Carslaw and J. C. Jaeger, The Conduction of Heat in Solids, 2d Edition, pp. 10-11 (Oxford Univ. Press, 1959).

[6] P. Vernotte, Formes diverses de l'equation de la chaleur. Equation intrinseque, Comp. Rend. Acad. Sci. 218, 39 (1944).

[7] Carslaw and Jaeger, op. cit., pp. 214-229.

[8] H. E. Robinson, Note on: Radiation imaging technique for thermal conductivity measurement above $1000{ }^{\circ} \mathrm{C}$, Rev. Sci. Instr. 33, 392 (1962).

[9] M. Hoch and D. A. Nitti, New Method for the determination of thermal conductivities between $1000^{\circ}$ and $3000{ }^{\circ} \mathrm{C}$, Aeronautical Systems Division Technical Report No. ASD TR 61-528 (June 1962).

(Paper 68C4-166) 